\title{
ON THE INFINITE GOD OBJECTION: A REPLY TO JACOBUS ERASMUS \& ANNÉ
}

\section{HENDRIK VERHOEF}

\begin{abstract}
Erasmus and Verhoef suggest that a promising response to the infinite God objection to the Kalām cosmological argument include showing that (1) abstract objects do not exist and (2) actually infinite knowledge is impossible, and (3) redefining omniscience as (G): For any proposition $p$, if God consciously thinks about $p$, God will either accept $p$ as true if and only if $p$ is true, or accept $p$ as false if and only if $p$ is false. I argue that there is insufficient motivation for showing (1) and (2) and that (G) is problematic as a definition of omniscience.
\end{abstract}

Keywords: infinite God objection; Kalām cosmological argument; abstract objects; omniscience

\section{Introduction}

In a recent article, Erasmus and Verhoef (2015) address a dilemma which they think is faced by proponents of the Kalām Cosmological Argument (KCA) who attempt to show that the number of past events cannot be actually infinite by arguing that actual infinities cannot exist. They frame the dilemma as follows: either an actual infinite can exist or God cannot be omniscient in the sense of knowing an actually infinite number of future events or abstract objects. They argue that a promising response is to show that

(1) abstract objects do not exist,

(2) actually infinite knowledge is impossible

(3) a definition of omniscience similar to $(G)$ is correct; where $(G)$ : For any proposition p, if God consciously thinks about $p$, God will either accept $p$ as true if and only if $p$ is true, or accept $p$ as false if and only if $p$ is false.

(4) God is atemporal without creation and yet temporal subsequent to creation. 
I shall argue that there is no sufficient motivation for proponents of KCA to show (1) and (2); moreover, I shall argue that (G) is problematic as a definition of omniscience.

\section{No sufficient motivation for showing (1) and (2)}

In their discussion of (1), Erasmus and Verhoef consider Moreland (2003)’s explanation that, although there exist an actually infinite number of abstract objects, an actually infinite number of concrete objects cannot exist in the real world. They object that 'The problem here is that it appears difficult to justify why the realm of abstract objects is exempt from such absurdities' (Erasmus and Verhoef 2015, 7). They argue that 'It is unhelpful to respond that this is the case because abstract objects are not spatio-temporally extended and, thus, cannot be added to or subtracted from anything - abstract objects can be added to and subtracted from many things,'(ibid, 7-8) and they provided a number of examples to substantiate their claim.

In reply, I shall demonstrate that one can modify Moreland's response so as to argue that certain kinds of concrete infinities, such as an actual infinite past, is metaphysically impossible, and justify why the realm of abstract objects is exempted. To begin, one needs to have a clear understanding of what, exactly, the nature of the absurdity in question is that would render certain kinds of concrete actual infinities (such as an actual infinite past) metaphysically impossible. 'Friends of infinity' have replied to Craig by arguing that the alleged absurdities which result from paradoxes such as Hilbert's Hotel have not demonstrated what the problem is supposed to be. For example, Graham Oppy has argued that 'In many cases, these allegedly absurd situations are just what one ought to expect if there were large and small denumerable, concrete infinities’ (Oppy 2006, 48). He adds, 'Furthermore it is very easy to make the mistake of supposing that, because certain kinds of large and small denumerable, concrete infinities really are impossible, it follows that all kinds 
of large and small denumerable, concrete infinities are impossible’ (ibid, 88-89). With regards to Hilbert's Hotel's ability to accommodate new guests by shifting rooms even though it is full, a friend of infinity will say that this is what ought to be expected of a hotel with an infinite number of rooms, and to assume otherwise would be to beg the question against the existence of an actual infinite. Philipse claims that

'Geog Cantor showed...these paradoxes of infinity arise because one mistakenly conceives of infinite sets on the model of finite sets. In order to avoid such confusions, infinite sets should be defined explicitly as sets that can be paired in a one to-one correspondence with a proper subset...After Cantor's elimination of the traditional paradoxes of infinity, it seemed to mathematically informed philosophers that the First -cause cosmological argument had been refuted conclusively.’ (Philipse 2012, 224).

Philipse thinks that Hilbert's hotel seems paradoxical merely because 'such things are physically impossible on Earth, so that it is perhaps psychologically impossible to imagine them.' (Ibid, 225-6). Thus merely asserting that there is a seemingly paradoxical result is not enough; one has to provide stronger arguments to show that the result is metaphysically impossible.

While Craig has argued that concrete infinities entail 'logically impossible situations, such as subtracting identical quantities from identical quantities and finding nonidentical differences,' (Craig and Sinclair 2009, 111-112) mathematician James East has replied that inverse operations of subtraction and division with infinite quantities do not lead to contradictions; they only lead to indefinite answers as one could get different answers depending on which objects one chooses to take away (East 2013). The phrase 'identical quantities' as used by Craig is ambiguous; while it is the case that the same number of guests is removed, it isn't the case that identical guests from identical rooms are removed; hence there is no logical contradiction. 
Nevertheless, the sort of reply East offers by no means proves that concrete actual infinities are possible. It should be noted that what is mathematically possible is not always metaphysically possible. For example, the quadratic equation $x^{2}-4=0$ can have two mathematically consistent results for ' $x$ ': 2 or -2 , but if the question is 'how many people carried the computer home', the answer cannot be '-2', for in the concrete world it is metaphysically impossible that '-2 people' carried a computer home. Thus the conclusion of '2 people' rather than '-2 people' is not derived from mathematical equations alone, but also from metaphysical considerations: ‘-2 people’ lack the causal powers to carry a computer home. This shows that metaphysical considerations are more fundamental than mathematical considerations.

In relation to this, Loke (2012) has argued that certain kinds of concrete infinities such as an actual infinite past is impossible because they would lead to a violation of a metaphysical necessary truth. He asks us to suppose there is a 'Christmas present generator' which has been generating similar Christmas presents at fixed temporal intervals as long as time existed. Suppose there is also a 'person generator' which has been generating persons at the same fixed temporal intervals as long as time existed. Suppose that the presents and the persons continue existing after they have been produced. He argues that the presence or absence of leftover presents should be independent of each person grabbing one present produced at any particular instant, because $(\mathrm{P})$ each person grabbing one present from one temporal position rather than another has no causal power with respect to the presence of leftover presents.

It is uncontroversial that $\mathrm{P}$ is metaphysically necessarily true for finite sets. The crucial question to ask is whether $\mathrm{P}$ is metaphysically necessarily true only for finite sets, or is it metaphysically necessarily true for 'any set with any number of concrete members' that can exist. Loke argues that it is a metaphysically necessary principle that the causal powers of 
a set of things ultimately depend on the things in the set and not the number in conjunction with the things. For example, suppose that a certain thing $\mathrm{Z}$ has zero mass. In this case, either a set of 'twenty' or 'ten' Zs would not make a difference to the reading on the weighing scale, because $20 \times 0=0$ and $10 \times 0=0$. And in cardinal arithmetic of Set Theory, infinity $\times 0=0$, because the product of any set A with the empty set is the empty set.

The point is that whether a set of things has certain causal power or not ultimately depends on the things (in the case of the Christmas present scenario, a thing= 'each person subsequently grabbing one present from one position rather than another'), and not the number in conjunction with the things. The reason is because 'number' is a mere abstraction of the things that exist in the set, and the 'number' of a set of things is not the sort of entity which in conjunction with the things in the set would have certain causal power that the things would not have had. Since that is the case, it cannot be claimed that the abstract number $n$ (whether finite or infinite) of person-present in conjunction with 'each person subsequently grabbing one present from one position rather than another' would make a difference concerning the presence or absence of causal power with respect to leftovers. ${ }^{1}$ Rather, the presence or absence of such causal power would ultimately depend on whether 'each person subsequently grabbing one present from one position rather than another' has any causal power, and the abstract number $n$ would be irrelevant.

Hence, the number of physical things in a set should not matter where the range of $\mathrm{P}$ over $z$ is concerned. Now we know that P ranges over any $z$ where $n$ is finite (both friends and opponents of infinity are agreed on this). However, since $n$ is irrelevant, it is not the case that $\mathrm{P}$ ranges over any $\mathrm{z}$ only where $n$ is finite; on the contrary, it is the case that $\mathrm{P}$ ranges over any $z$ for any $n$. Hence, P is metaphysically necessarily true, not merely 'for finite sets', but for ‘any sets with any number of members’ that can exist.

\footnotetext{
${ }^{1}$ Peter Lyth claims that Loke's argument conflates number as a number of events or things with number as an abstract entity (Lyth 2014, 85-88). This claim is false, because 'number' is understood in the same sense throughout the argument, i.e. as an abstract entity with no independent causal power.
} 
Loke goes on to explain that $\mathrm{P}$ will be violated if there were an actual infinite past: suppose at time $t 0$ the person who was generated at $t-1$ picked up the present generated at $t$ 1 , the person who was generated at $t-2$ picked up the present generated at $t-2$, the person who was generated at $t$-n picked up the present generated at $t-n$...If there were an infinite temporal regress of events, the result is that there would not be an infinite number of presents left. But if they had grabbed the presents this way: the person who was generated at time $t-1$ picked up the present generated at $t-2$, the person who was generated at $t-2$ picked up the present generated at $t-4$, the person who was generated at $t-n$ picked up the present generated at $t-2 \mathrm{n} .$. If there were an infinite temporal regress of events, what happens is that each person would walk away with one present, and there would be an infinite number of presents left! The problem arises from the postulation that these generators existed from an actual infinite past, for if they did not exist from an actual infinite past, such situations which violate metaphysical necessity truth $\mathrm{P}$ would not have arisen. Hence, an actual infinite temporal regress of events is metaphysically impossible.

The above scenario indicates that the problem with certain kinds of concrete infinities is related to the fact that the members of the set are embedded in a network of causal relations and which involve the violation of metaphysical necessary truth. Since it can be postulated that an actual infinite of abstract entities are not embedded in a network of causal relations and do not involve such violations, the realm of abstract objects is exempted. By making this sort of move, proponents of the Kalam Cosmological Argument can accept Platonism and also allow for an actual infinite number of abstract entities, but argue that an actual infinite past does involve such a violation and thus is metaphysical impossible.

I shall now respond to the following thought experiment which Erasmus and Verhoef use to illustrate the problem confronting infinite knowledge: 
'Suppose Jones and Smith possess identical knowledge and they both know an actually infinite number of mathematical equations only, namely, Jones and Smith only know that $1+1=2,1+2=3,1+3=4$ and so on ad infinitum. Suppose, furthermore, that Smith somehow forgets and loses his knowledge of every second mathematical equation that he previously knew, that is, Smith no longer knows that $1+2=3,1+4=5,1+6=7$ and so on ad infinitum. Smith’s knowledge, however, still encompasses an actually infinite number of propositions. Therefore, although Jones knows an infinite number of propositions that Smith does not know, Jones and Smith know exactly the same amount of propositions. Consequently, infinity minus infinity equals infinity. Now, suppose that Smith forgets and loses his knowledge of all but the first seven equations that he previously knew, that is, after forgetting an actually infinite number of propositions Smith now only knows seven propositions. In this case, infinity minus infinity equals seven. However, this result is an absurdity, namely, infinity minus infinity equals infinity, yet infinity minus infinity equals seven! This illustrates that, when it comes to the abstract infinite, one may subtract or divide equal quantities from equal quantities and, yet, reach different results. The situation could become even more peculiar. Suppose that Jones, somehow, becomes omniscient and, therefore, acquires knowledge of all true propositions (according to the very broad definition of omniscience). Jones now possesses knowledge of an actually infinite number of propositions (assuming that there are an actually infinite number of true propositions), which is identical to the number of propositions that he knew before he was omniscient. So, a nonomniscient person may know exactly the same number of propositions (abstract objects) that an omniscient person knows!' (Erasmus and Verhoef 2015, 8).

In reply, I shall defend a modified version of Craig's proposal that the mode of God's knowledge has no propositional structure but rather is an 'undivided intuition' (the difference 
between Craig's proposals and mine is that, while Craig has argued that abstract entities do not exist, my proposal affirms the existence of abstract entities, as I shall explain below).

With regards to the question whether God knows every truth, Craig explains

'When we define omniscience as knowledge of only and all true propositions, we are expressing the extent of God's knowledge, not its mode. The mode of God's knowledge has traditionally been taken to be non-propositional in nature. God has a single undivided intuition of reality, which we finite knowers break up into individual bits of information called propositions.' $^{2}$

Citing William Alston (1986), Craig maintains that 'God’s knowledge is strictly nonpropositional, though we represent it to ourselves as knowledge of distinct propositions,' and he uses the analogy of one's visual field, which one sees as an undifferentiated whole, but which could be analyzed as composed of pixels. Craig goes on to explain

'What is true to say and what God knows is that according to standard number theory, there is an actually infinite number of numbers. Moreover, God knows that an actually infinite number of arithmetic truths follow from the axioms of standard arithmetic, like $1+1=2,2+1=3,3+1=4, \ldots$ But, as explained above, He does not know these truths propositionally, as I have just expressed them, but non-propositionally. ${ }^{3}$

I shall now elaborate on my own understanding of Craig's view that the structure of the mode of God's knowledge is a non-propositional, undivided intuition. Intuition can be understood as a form of intellectual seeming that does not require sense perception. And just as the objects of non-propositional acquaintance can include propositions (Fumerton 1995, 75), the objects of God's non-propositional intuition can include propositions, properties or states of affairs. Craig's statement 'God’s knowledge is strictly non-propositional, though we represent it to ourselves as knowledge of distinct propositions' does not need to be

\footnotetext{
${ }^{2}$ http://www.reasonablefaith.org/is-god-actually-infinite. Accessed 22/8/15.

${ }^{3}$ http://www.reasonablefaith.org/does-god-know-an-actually-infinite-number-of-things Accessed 22/8/15.
} 
understood as claiming that all forms of non-propositional knowledge can be described in propositional terms (many philosophers have argued that certain non-propositional knowledge, such as knowledge of what chocolate tastes like, cannot be fully described by propositions). Rather it can be understood as claiming that what is represented in our minds as discrete propositions can be represented in a different manner in the mind of God. As noted earlier, Craig uses the analogy of pixels and visual field. In a similar vein, God can think of the following two propositions 'there is a tree 1 meter in front of Peter,' 'there is another tree 2 meters in front of Peter' in terms of a mental image of Peter and two trees. An undivided, non-propositional intuitive knowledge of propositions is different from a propositional intuitive knowledge of propositions, in that they describe different manners in which knowledge of the same things is represented in the mind.

Elsewhere, Craig has argued that abstract entities do not exist, but others have objected to his views (see Gould 2014). ${ }^{4}$ I shall explain in the next section of the paper that, in any case, rejecting the existence of abstract entities and arguing that these are merely useful fictions does not help to solve the problem posed by the thought experiment suggested by Erasmus and Verhoef. But before that, I shall first show in the rest of this section that one can modify Craig's position by affirming the existence of abstract entities, and defend the view that God's undivided intuition does encompass an actually infinite number of abstract objects including all mathematical and future truth values.

Erasmus and Verhoef would object, 'Even if God knows these truths nonpropositionally, what happens if (like Smith) he were to lose his non-propositional knowledge of every second mathematical equation that he previously knew?'

\footnotetext{
${ }^{4}$ Erasmus and Verhoef also mention the problem of abstract objects for the doctrine of divine aseity, the discussion of which is beyond the scope of this article; suffice to note that various solutions which preserve the existence of abstract objects have been offered: see Gould (2010) and Gould (2014).
} 
One might reply to the thought experiment by arguing that it presupposes that a person can lose a subset of his knowledge or acquire additional knowledge, but this is metaphysically impossible with God, because God's perfect knowledge is immutable.

But let us suppose for the sake of the argument that a divine person can lose a subset of his knowledge. One can argue that this does not pose a problem as long as the mode of his knowledge remains as an ‘undivided intuition’ rather than as an actual infinite number of concrete parts or manifesting as an actual infinite number of concrete entities (such as making a Christmas present for each number that he knows and causing all of them to exist simultaneously). Proponents of KCA can argue that the latter act is metaphysically impossible because concrete actual infinities cannot exist, ${ }^{5}$ and the fact that God cannot do such an act does not violate divine omnipotence because divine omnipotence does not require God to do what is metaphysically impossible (such as creating a shapeless cube). ${ }^{6}$

Erasmus and Verhoef might complain that God's knowledge remaining as an 'undivided intuition' does not solve the problem, for the fact remains that the number of truths he knows after losing a subset could either still be same as before or reduced to seven, thus the paradoxical consequences of 'infinity minus infinity equals infinity' and 'infinity minus infinity equals seven’ remains.

One might respond that the number of truths that is being known by God remains in the abstract; they are not being held in God's mind as an actual infinite number of entities but rather are known by an 'undivided intuition', and as explained above there will never be a time at which all the truths known are actualised as concrete entities. The problem that 'the

\footnotetext{
${ }^{5}$ Or at least certain kinds of concrete infinities cannot exist; a proponent of the Kalam can allow kinds of concrete infinities other than an actual infinite past, as long as they do not violate metaphysical necessary truths. ${ }^{6}$ One might ask: if this qualification is allowed for divine omnipotence, why not allow it for divine omniscience, i.e. allow for a divine person not to possess actual infinite knowledge because it is metaphysically impossible? In reply, as explained below it does not seem that actual infinite knowledge is metaphysically impossible. Additionally, given that the existence of an actual infinite number of abstract propositions remains defensible (see Gould 2014) it would seem to impinge on divine perfection to say that there are some of them which God does not know.
} 
number of truths he knows after losing a subset could either still be same as before or reduced to seven' remains in the abstract, and hence they do not cause problems in the concrete world.

However, Erasmus and Verhoef might object that, even if there are not an actual infinite number of concrete entities in the undivided intuition of the mind of a person knowing an actual infinite number of truths, nevertheless the idea that a non-omniscient person (who, for example, knows an actually infinite number of mathematical equations only) may know exactly the same number of propositions that an omniscient person knows remains paradoxical. The problem does not merely concerns the abstract realm of entities that are known by the minds of Smith and Jones, rather the problem concerns the concrete entities, viz. the minds of Smith and Jones who know of an actual infinite number of abstract entities.

In response, the minds of Smith and Jones are not strictly speaking concrete infinities given that each of them does not consist of an actual infinite set of concrete parts. Rather, in accordance with my proposal, each mind can be understood as a single undivided intuition that encompasses an actual infinite of abstract entities. Moreover, it has been explained above that merely asserting that the result is seemingly paradoxical is not enough; one has to provide stronger arguments to show that the result is metaphysically impossible. In this case, such an argument seems unavailable. On the other hand, one might affirm that the result that the mind of Smith knows the same number of abstract entities as the mind of Jones ('infinity minus infinity equals infinity’) or infinitely less ('infinity minus infinity equals seven’), depending on which abstract equations are forgotten, is only to be expected. This is so given that they both encompass an actual infinite number of abstract entities, given the definition of an abstract infinite set as one in which a part of it can be put into a one-to-one correspondence with the whole, and given that two sets are said to have the same number of members if the members of one set can be related to the members of the other set in a one-toone correspondence. As noted earlier (citing James East), inverse operations of subtraction 
with infinite quantities do not lead to contradictions but only to indefinite answers, depending on what is subtracted. One can argue that this is not a problem as long as there is no violation of metaphysical necessary truths such as the one described earlier concerning an actual infinite past.

\section{(G) is problematic as a definition of omniscience}

On the other hand, the alternative view of divine omniscience which Erasmus and Verhoef defend is problematic. They argue that the objects of God's knowledge do not have to be present all at once, thus avoiding an actual infinite existing within God's mind. They suggest rephrasing the standard definition of omniscience as follows:

(G) For any proposition $p$, if God consciously thinks about $p$, God will either accept $p$ as true if and only if $p$ is true, or accept $p$ as false if and only if $p$ is false (Erasmus and Verhoef 2015, 13-14).

In response, a problem with $(G)$ is that it defines omniscience in terms of conscious awareness. However, knowledge and conscious awareness are not the same. There is controversy in philosophical literature concerning the definition of knowledge. Many contemporary philosophers analyse it in terms of justified true beliefs with responses to Gettier problems, while others regard it as unanalyzable. In any case, there is a distinction between knowledge and conscious awareness, that is, for any person $p$ to possess knowledge of $y$ it is not required that $p$ 's knowledge of $y$ be consciously held. In other words, it is not required that p's knowledge of $y$ be occurrent rather than dispositional. Philosopher Robert Audi explains the distinction between occurrent and dispositional beliefs as follows:

'What is dispositionally as opposed to occurrently believed is analogous to what is in a computer's memory but not on its screen: the former needs only be brought to the screen by scrolling a simple retrieval process in order to be used, whereas the latter is before one's eyes. compare a dispositionally believed proposition's needing to be 'called in', as in answering a 
request to be reminded of what one said last week, with an occurrently believed proposition's being focally in mind, roughly in the sense that one attends to it, as where one has just formulated it to offer as one’s thesis.' (Audi 1994, 420)

I agree with Erasmus and Verhoef that, given that one can know something that one is not consciously aware of, the number of propositions an omniscient God is consciously thinking about does not have to be an actual infinite (this idea has been used for making sense of the doctrine of the Incarnation; see Loke 2014, 114). Indeed I agree with them that 'a person who is entertaining only those ideas that are the best to entertain appears to be greater than a person who is not able to control his/her conscious thought and is constantly engulfed in an infinite number of unnecessary thoughts' (Erasmus and Verhoef 2015, 16). However, the crucial question is not how many propositions God is consciously thinking about. Rather, the crucial question is how many propositions God knows about, and Erasmus and Verhoef has merely sidestepped this question by defining omniscience in terms of conscious awareness.

In another part of the paper Erasmus and Verhoef deny the existence of abstract objects, suggesting that 'abstract objects are similar to fictional characters in that a person may think and talk about abstract objects despite the fact that they do not exist’ (ibid, 14). They compare abstract objects to 'Sherlock Holmes', which does not denote any actually existing object, and claim that ' $p$ does not denote an unactualised future event that exists. Rather, $p$ is simply an imaginary, fictional proposition that is no more than a thought in one's mind. Hence, if God is thinking about $p$, then, God's thought about $p$ exists, yet $p$ itself does not exist. Accordingly, God is able to construct mental images denoting such fictional propositions, mathematical equations, numbers or future events, without requiring that these objects exist independently of God's conscious thought. In that case, an actual infinite may be present in the mind of God only if God consciously thinks about each and every member of 
an endless series of propositions all at once' (ibid). They also suggest that 'omniscience should fundamentally be understood as maximal knowledge. To say that God has maximal knowledge is to say that God possesses the most perfect knowledge attribute that is attainable, namely, the ability to identify the truth value of any proposition simply by consciously thinking about the proposition' (ibid, 13).

However, the ability to identify the truth value of any proposition would seem to require the knowledge of all propositions to be already in God's mind in some sense, regardless of whether propositions are understood as fictional or not. If Erasmus and Verhoef want to claim that God does know an actual infinite number of fictional propositions such that, if God consciously thinks about any proposition $p$, He will either accept $p$ as true if and only if $p$ is true or accept $p$ as false if and only if $p$ is false, then they still have not answered the crucial question how does He know an actual infinite number of fictional propositions, and what happens if He (like Smith) were to forget and loses his knowledge of every second fictional mathematical equation that he previously knew (that is, if He no longer accepts $1+2=3,1+4=5,1+6=7$ etc. as true). In that case, does He still know the same number of fictional propositions as He knew before?

\section{Conclusion}

In conclusion, I have argued that proponents of the Kalām cosmological argument do not have to follow Erasmus and Verhoef's suggestion to reject the existence of abstract objects and the possibility of actually infinite knowledge, and that their redefinition of omniscience does not solve the problem in any case.

\section{References}

Alston, William (1986). Does God Have Beliefs? Religious Studies 22: 287-306.

Audi, R. (1994). 'Dispositional beliefs and dispositions to believe’. Noûs 28: 419-34. 
Craig, William Lane and James Sinclair (2009). The Kalam Cosmological Argument, in The Blackwell Companion to Natural Theology, ed. William Lane Craig and J.P. Moreland, Oxford: Blackwell: 101-201.

East, James (2013). Infinity minus infinity, Faith and Philosophy, 30: 429 - 433.

Erasmus, Jacobus and Anné Hendrik Verhoef (2015). The Kalām Cosmological Argument and the Infinite God Objection. Sophia. DOI 10.1007/s11841-015-0460-6

Fumerton, Richard (1995). Metaepistemology and Skepticism. Lanham, MD: Rowman and Littlefield.

Gould, Paul (2010). A Defense of Platonic Theism. PhD diss., Purdue University

Gould, Paul (ed.) (2014). Beyond the Control of God?: Six Views on the Problem of God and Abstract Objects. London: Bloomsbury.

Moreland, J. P. (2003). A response to a Platonistic and to a set-theoretic objection to the kalam cosmological argument. Religious Studies, 39, 373-390.

Loke, Andrew (2012). Is an infinite temporal regress of events possible? Think 11:105-122.

Loke, Andrew (2014). A Kryptic Model of the Incarnation. Farnham: Ashgate.

Lyth, Peter (2014). A response to Loke’s 'Is an infinite temporal regress of events possible?' Think 13:85-88.

Oppy, Graham (2006). Philosophical Perspectives on Infinity. Cambridge: Cambridge University Press.

Philipse, Herman (2012). God in the Age of Science?: A Critique of Religious Reason. Oxford: Oxford University Press. 